\title{
Displacement in Nigeria: Scenes from the northeast
}

Now in its ninth year, the armed conflict in Nigeria has forced more than 2 million people from their homes, with more than 1.5 million of these displaced within the country. The regionalized conflict-which since 2013 has affected the neighbouring countries of Cameroon, Chad and Niger-has caused a protracted humanitarian crisis with some of the highest human costs in the world. The most affected area in Nigeria is the northeast of the country, primarily the States of Adamawa, Borno and Yobe.

Those that have fled their homes often face numerous difficulties as they are left with nothing. In these dire situations, many have basic needs that have to be addressed: lack of food and water, access to health, shelter and education, mental health consequences, safety. Family separation is especially hard as in the chaos of violence, family members lose contact with their loved ones.

Most uprooted people gather in and around places such as Maiduguri and other camps in Borno and Adamawa. Northeast Nigeria is an underdeveloped area, and the humanitarian crisis takes a toll on both new and long-term displaced, returnees, host communities and hard-to-reach rural communities. A total of around 7 million people are in need of humanitarian assistance.

In the following gallery, photographer Newsha Tavakolian gives us a glimpse into the lives of displaced persons in northeastern Nigeria. 


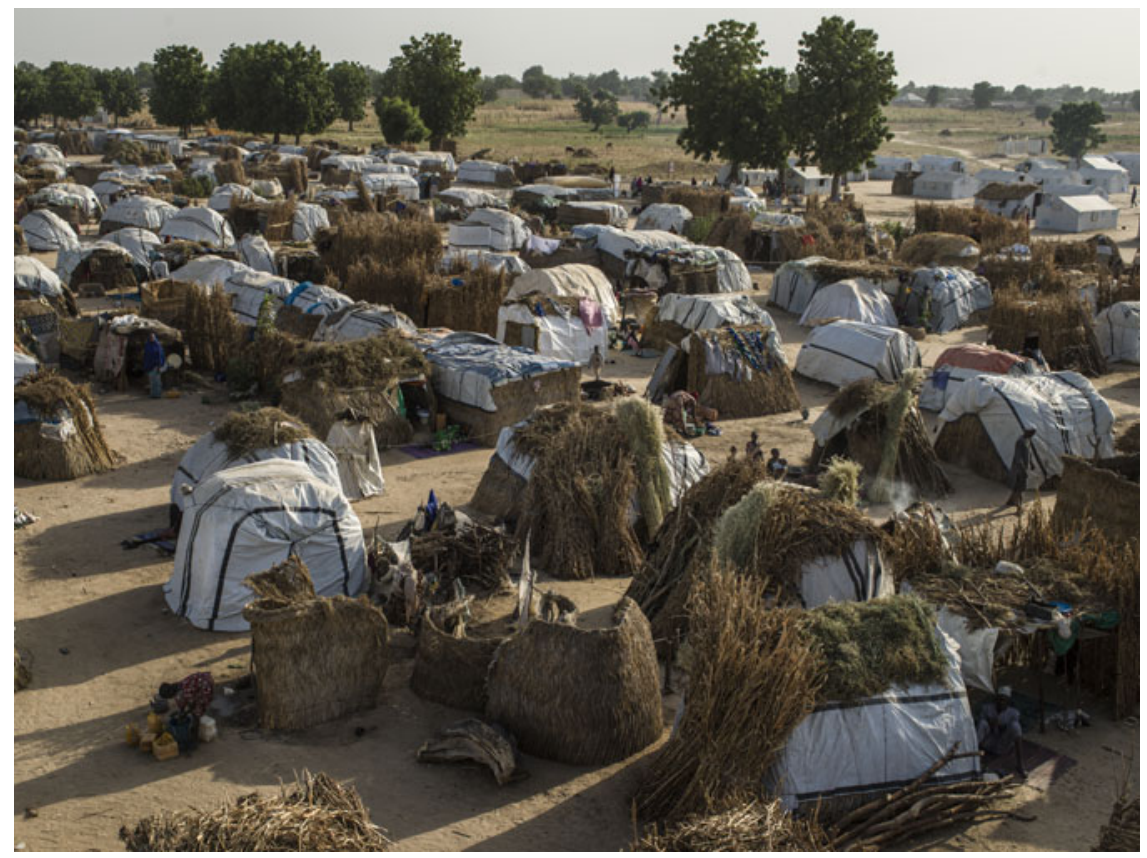

Figure 1. A view of the Muna camp for displaced persons, located just outside of Maiduguri, Nigeria. Continued violence in the northeast has forced residents to flee their villages, and many of them have come to the Maiduguri area seeking safety. Today the camp is estimated to shelter approximately 24,000 displaced people. All photos (c) Newsha Tavakolian/Magnum Photos for the ICRC. 


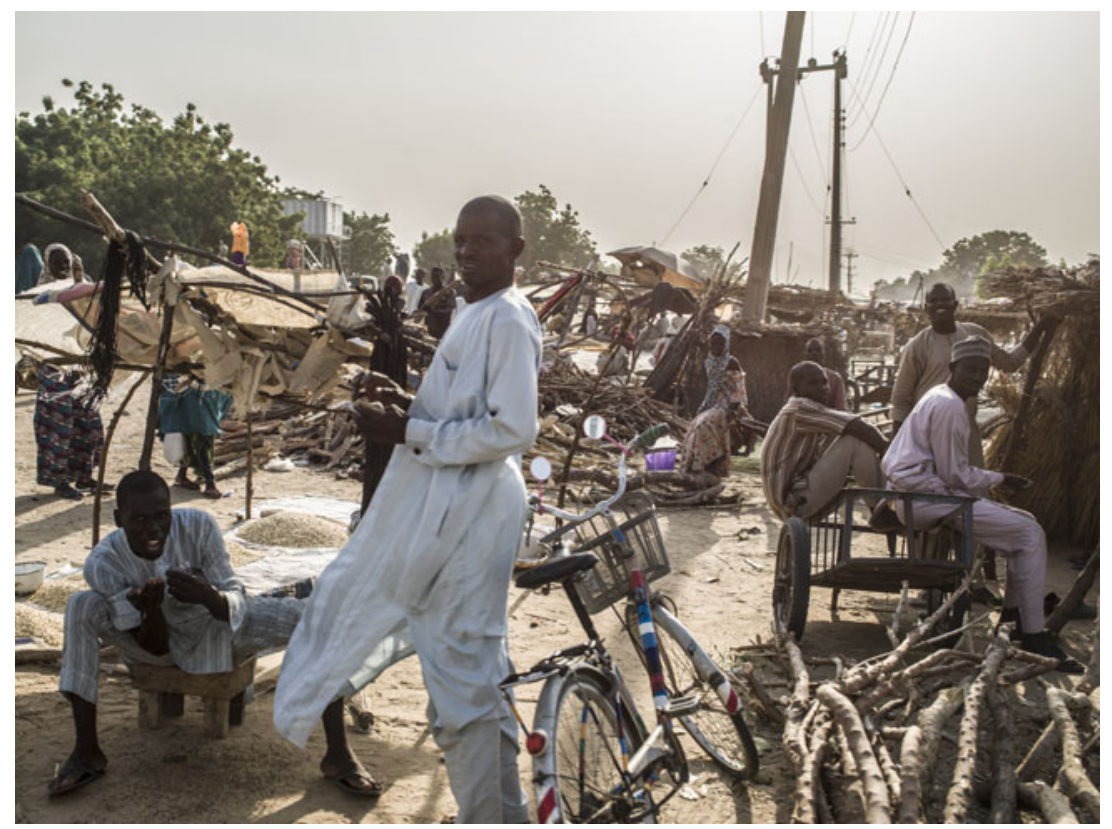

Figure 2. A wood market outside of the Muna camp, where wood is sold to people both inside and outside of the camp. 


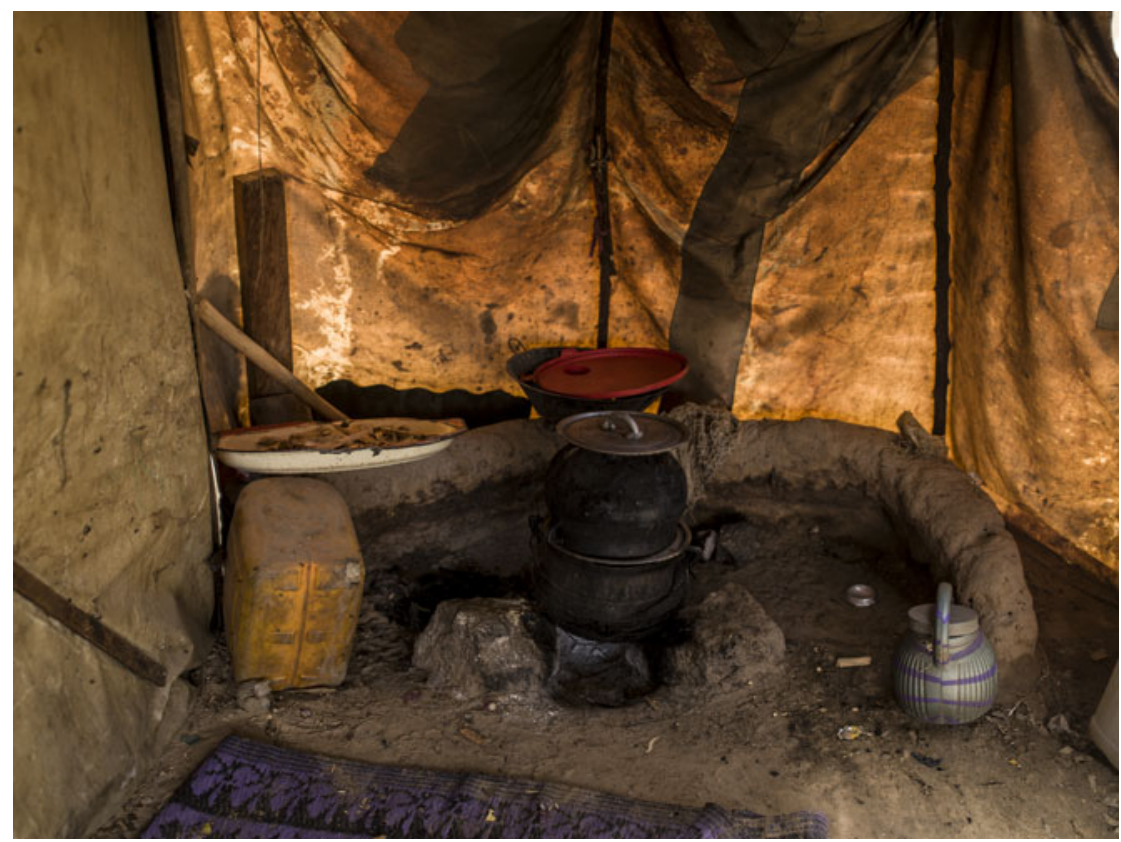

Figure 3. The home of Asami, a father of twelve, from the town of Bama. After not seeing six of his children for over seven years, he was reunited with two of them, but four are unaccounted for to this day. "At the time we lost [our two sons] they were 8 and 9 years old, and now they are 14 and 15", he says. The ICRC's Restoring Family Links (RFL) programme works to trace and reunite families separated by the chaos of violence, offering services that include phone calls, sending messages, and family reunifications. 


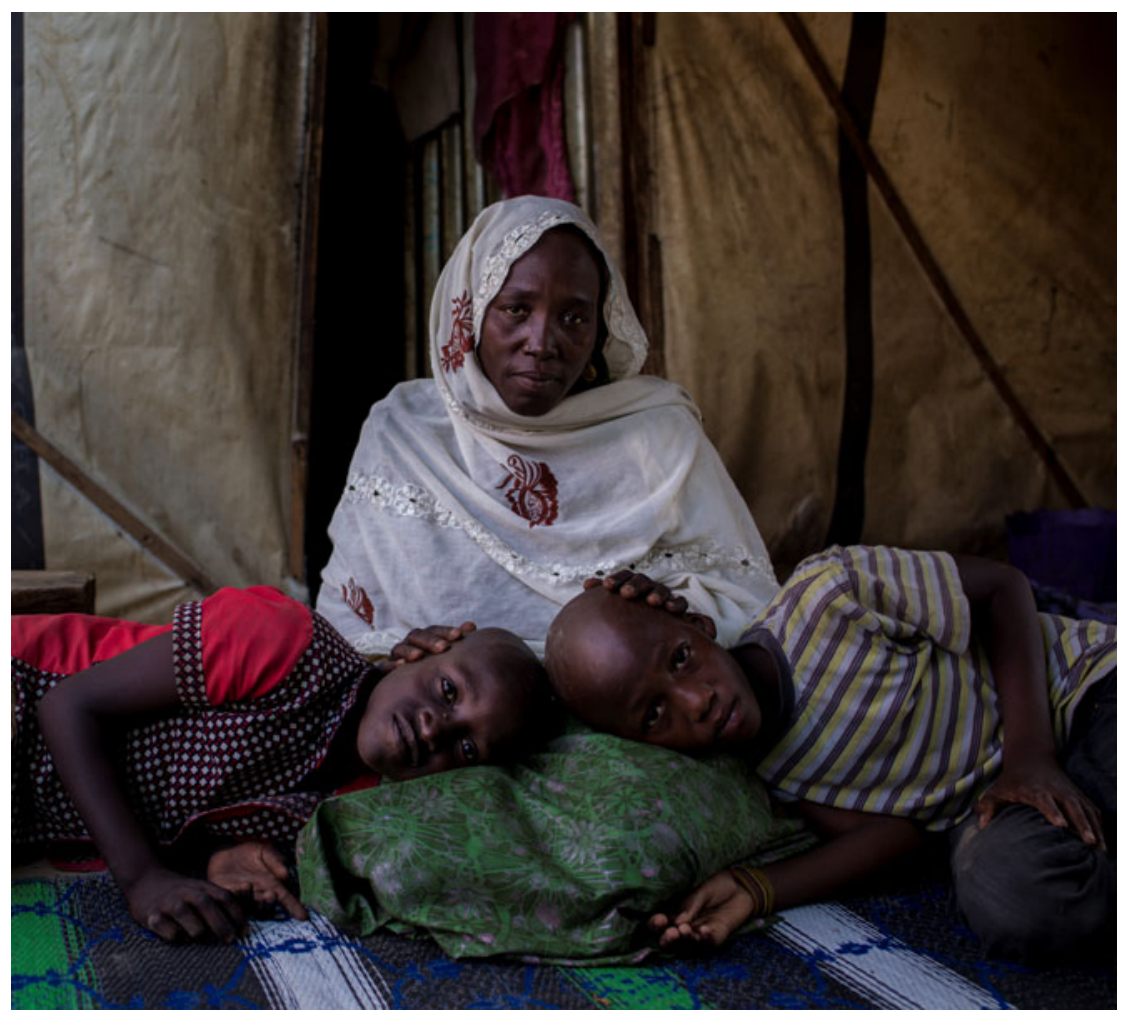

Figure 4. Roghiya, mother of twelve and wife of Asami, is seen with her two sons after being reunited through the RFL programme. Abuali and Muhammad, eight and nine years old, left the family to attend religious school seven years before this photo was taken. They explained that their teacher disappeared and the kids were left alone. The school was far from their home, and they were forced to live on the street without food and clean drinking water for months. Another teacher who found them and took them in for nearly two years gave their names to the ICRC's RFL delegate in hopes of finding their parents. Roghiya explains that her three daughters, who were also enrolled in the school, went missing after the attack. "Since then, we have no news from them and it's been seven years now that they are apart from us," she says. "Even when I am sleeping, I am always thinking of my children and wondering where they are; even when I am eating I imagine them sitting next to me and eating with me. My dreams are like a series." 


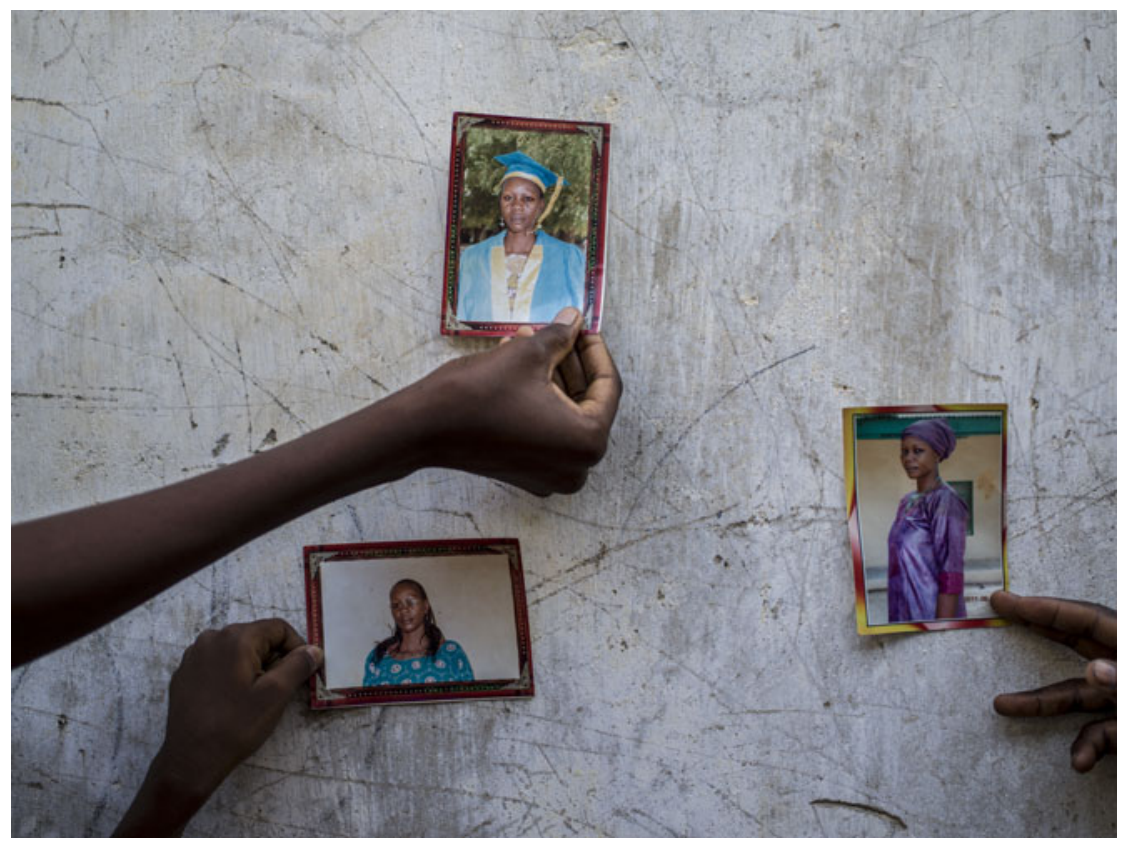

Figure 5. Paulina, 42, was abducted during an attack as she was attending her sister's funeral. Since then her family has had no news from her. Paulina's 16-year-old daughter Jummai reflects on her family's daily life after the abduction: "We have no news since the day she was abducted. Life is very hard for us. My mother was a woman who took care of everything with the household. Now we go to school and come back hungry." Paulina's husband adds: "She was everything for this house; she used to cook and clean and bring money to the family. Without her we really don't know how to survive." 


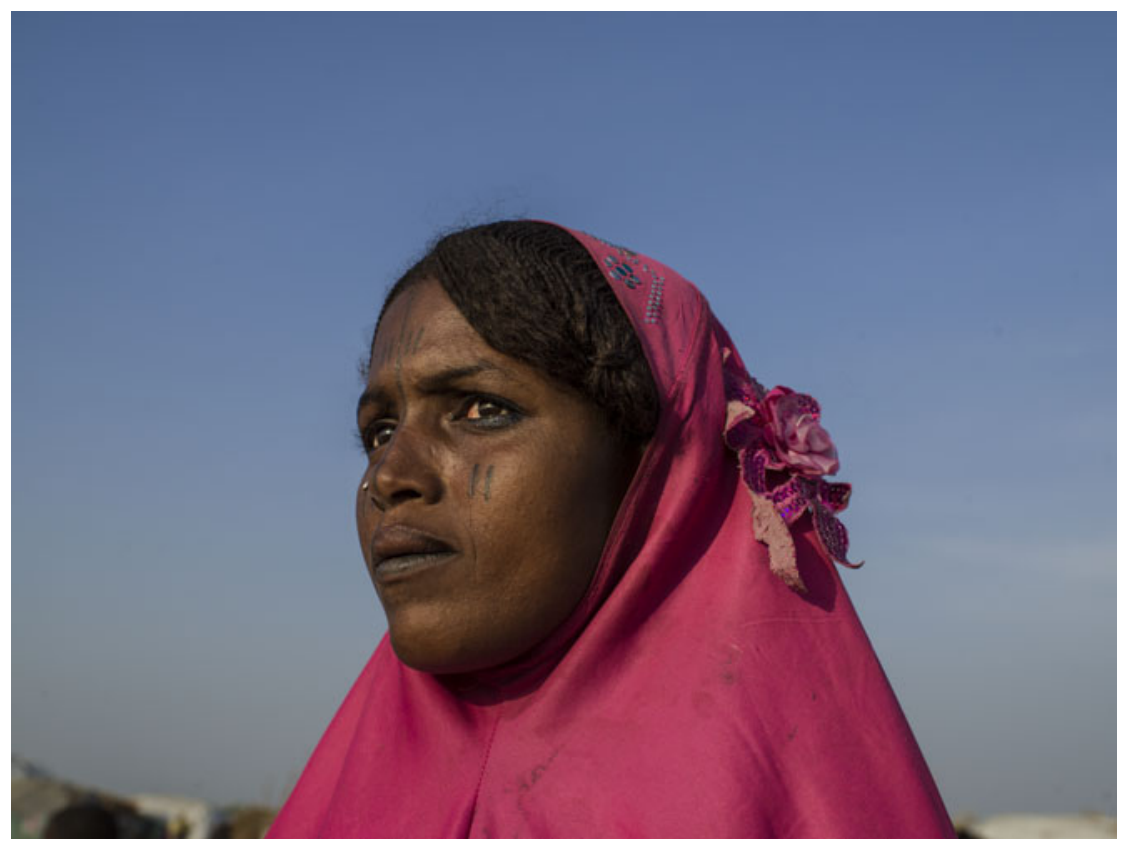

Figure 6. A resident at a camp for displaced persons in Maiduguri. 


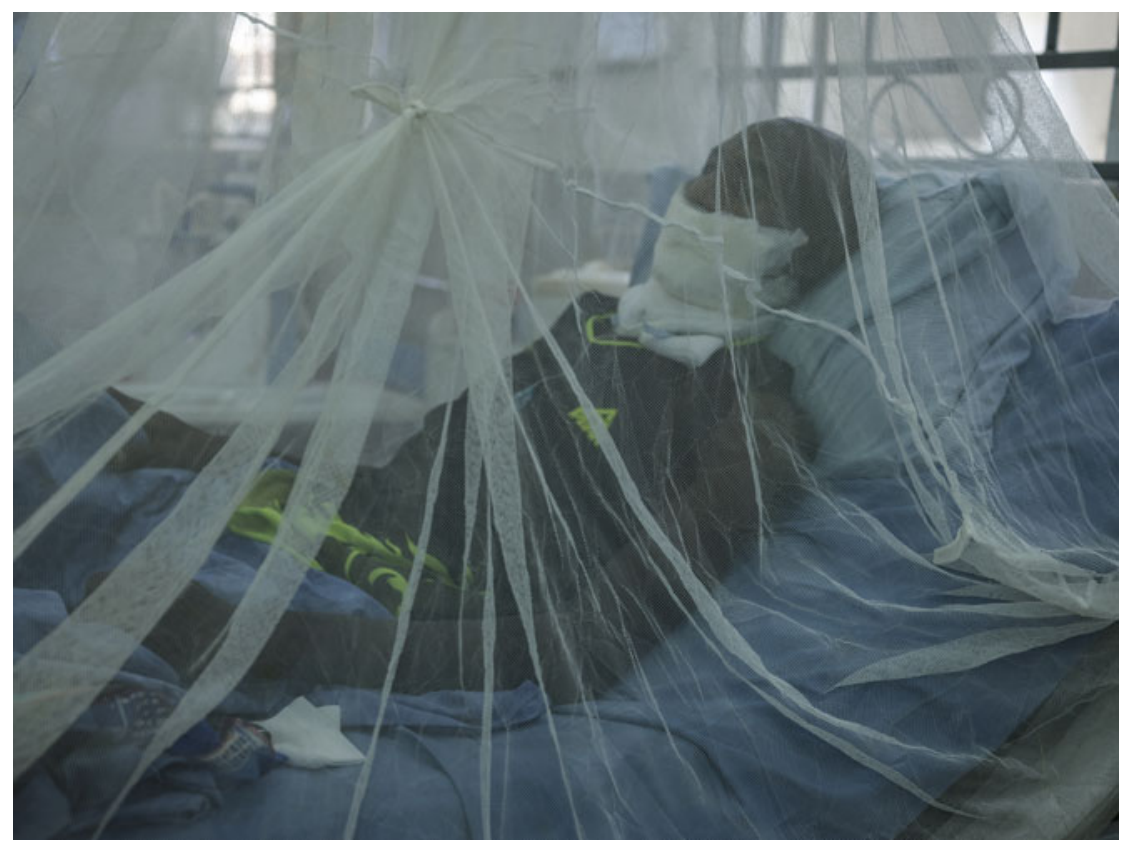

Figure 7. Alhaji, 34, from Ngala, recuperates after surgery in the State Specialists Hospital in Maiduguri. He was sleeping at home when he was shot in the throat. Two ICRC surgical teams tend to weapon-wounded and to displaced persons in need of surgical care at the hospital. 


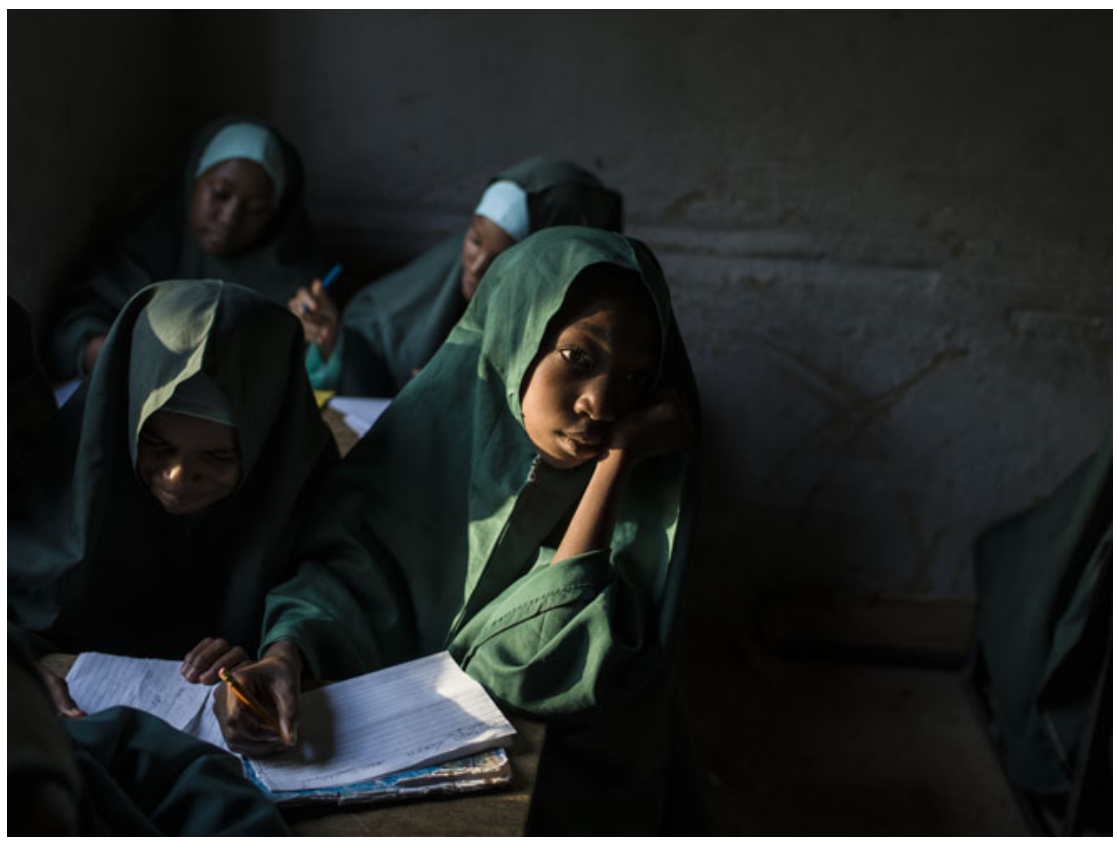

Figure 8. Students attend class at the Future Prowess Islamic School in the city of Maiduguri. The school was set up in 2009 for orphans and vulnerable children, offering both a Western and Islamic education to both boys and girls for free. The ICRC supports the school with food donations that are used to feed the children once a day. Some of their parents are widows who benefited from the ICRC livelihood support programme. 


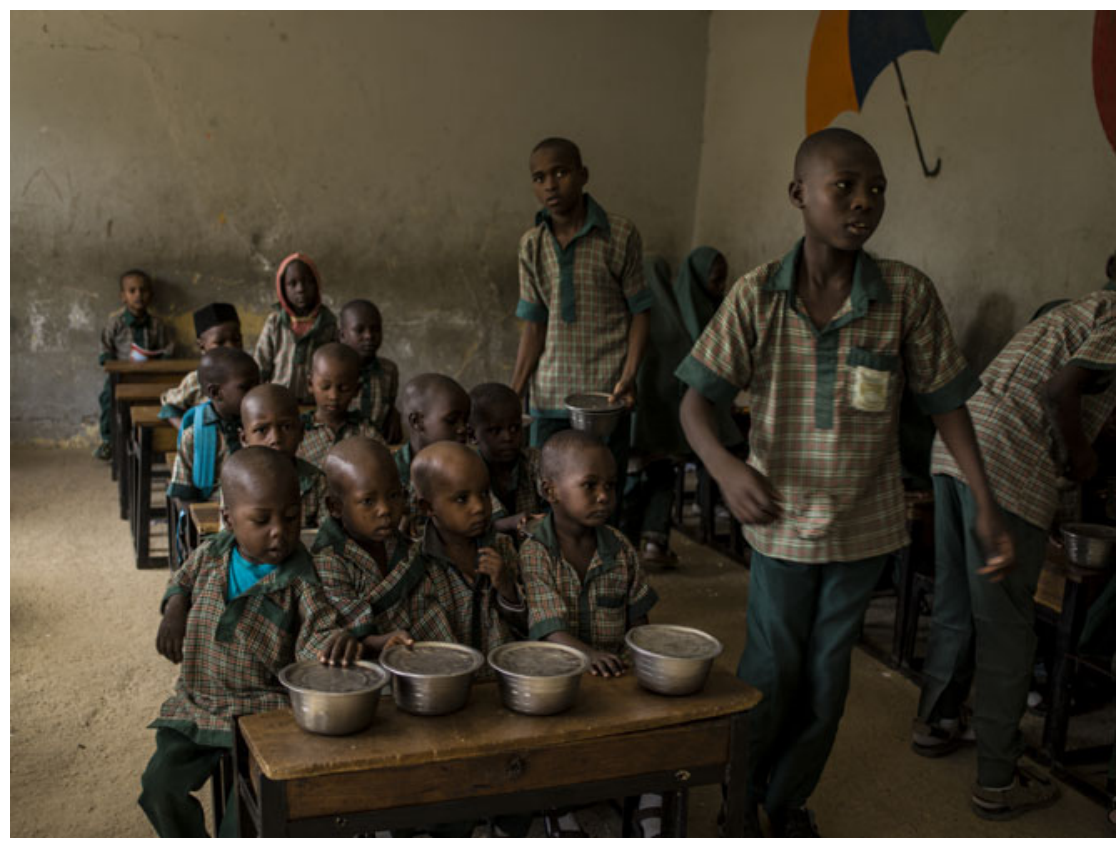

Figure 9. Children prepare for their meal at the Future Prowess Islamic School. 


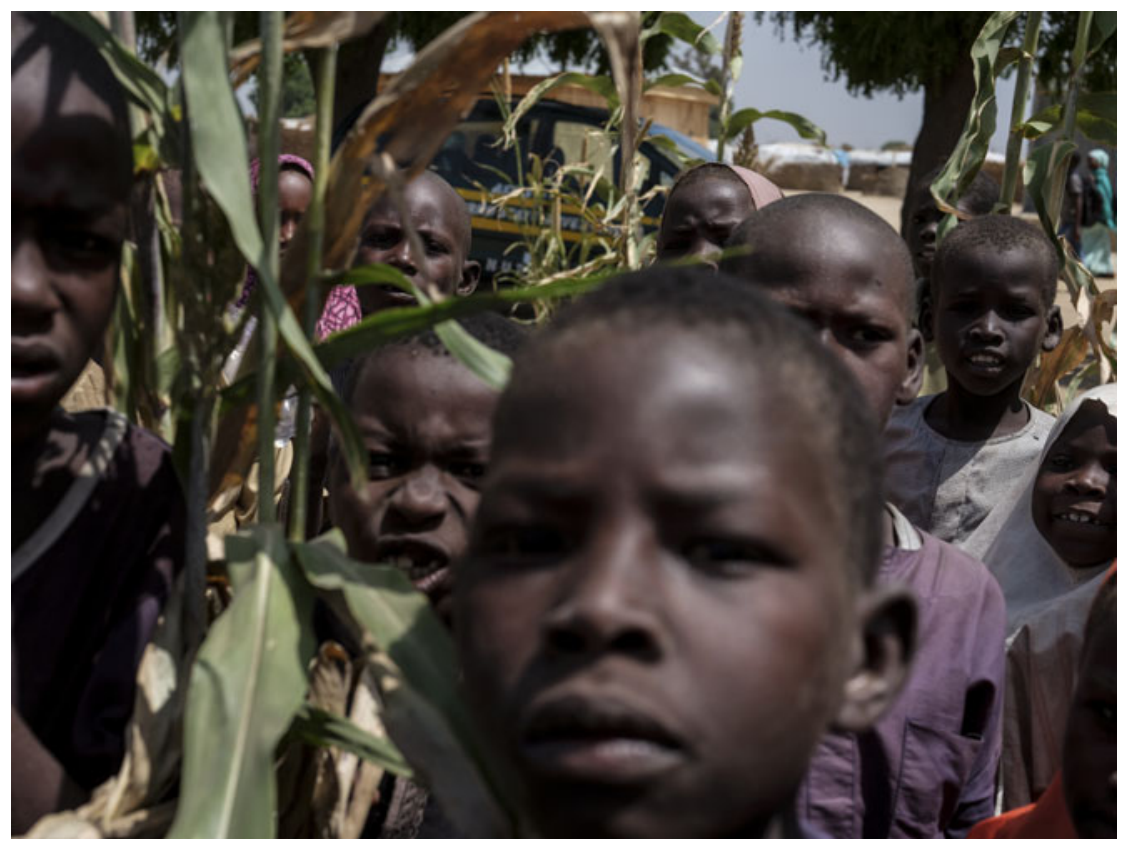

Figure 10. Children from a school in the Muna camp. 


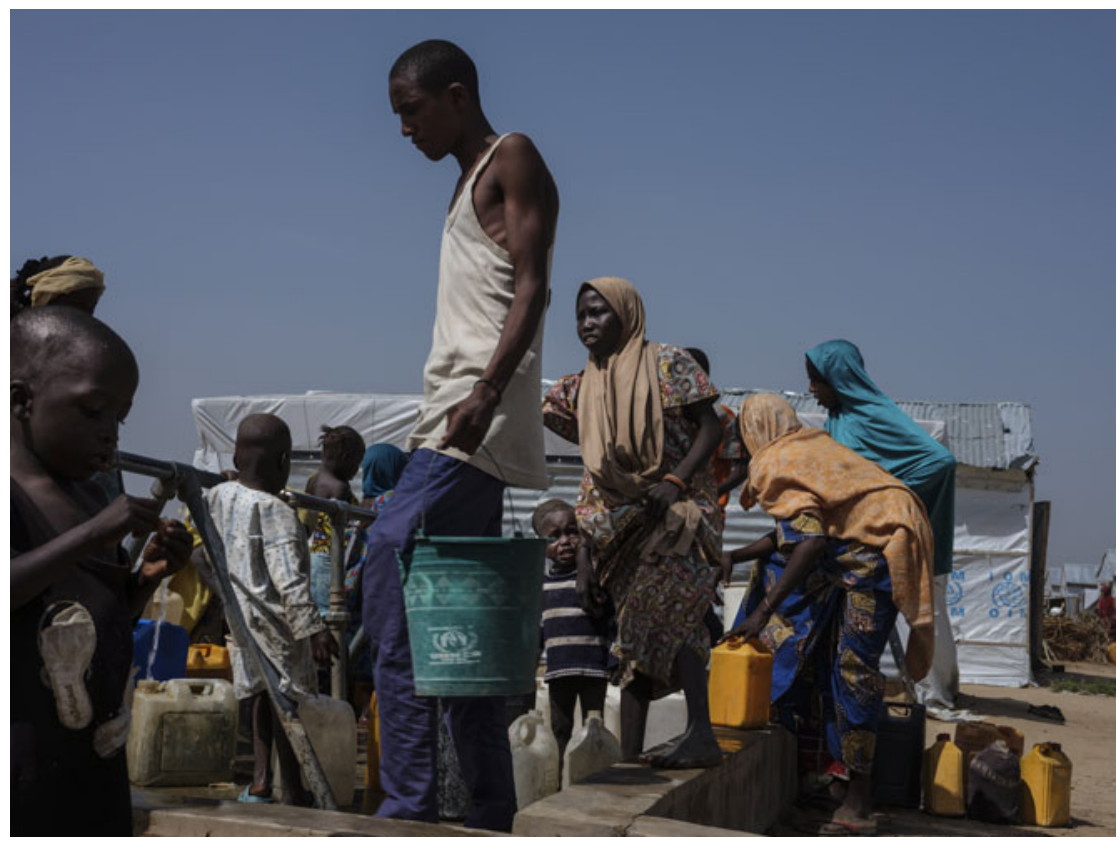

Figure 11. People line up to collect water in the Muna camp. 